\title{
Evaluation of the Effectiveness of a Paper Containing Nanoparticles of Silver Combined with Moisture Absorbers Over Quality of Tuna Snacks
}

\author{
David A. Pereira de Abreu ${ }^{1}$, Miguel A. Lago ${ }^{1}$, Antonio Sartal ${ }^{2}$, Ana Rodríguez-Bernaldo de Quirós ${ }^{1}$ and Raquel Sendon ${ }^{*}$ \\ ${ }^{1}$ Department of Analytical Chemistry, Nutrition and Bromatology, Faculty of Pharmacy, University of Santiago de Compostela, 15782-Santiago de Compostela, Spain
} ${ }^{2}$ Department of Business Administration and Product Design, University of Girona, 17071-Girona, Spain

Correspondence to:

Raquel Sendon

Department of Analytical Chemistry

Nutrition and Bromatology, Faculty of Pharmacy

University of Santiago de Compostela

15782-Santiago de Compostela. Spain

Tel: +34881814964

E-mail: raquel.sendon@usc.es

Received: January 25, 2016

Accepted: April 18, 2016

Published: April 29, 2016

Citation: Pereira de Abreu DA, Lago MA, Sartal A, Rodríguez-Bernaldo de Quirós A, Sendón R. 2016. Evaluation of the Effectiveness of a Paper Containing Nanoparticles of Silver Combined with Moisture Absorbers Over Quality of Tuna Snacks. J Food Chem Nanotechnol 2(2): 85-91.

Copyright: (C) 2016 de Abreu et al. This is an Open Access article distributed under the terms of the Creative Commons Attribution 4.0 International License (CC-BY) (http://creativecommons. org/licenses/by/4.0/) which permits commercial use, including reproduction, adaptation, and distribution of the article provided the original author and source are credited.

Published by United Scientific Group

\begin{abstract}
The antimicrobial activity of nanoparticles of silver in an active packaging and the effect of its combination with moisture absorbers over various parameters of the quality of tuna snacks was investigated. As a results, aerobic mesophilic bacteria growth were delayed during the first eight days of study; enterobacteria do not grow in snack tuna samples packaged with nanoparticles of silver and molds and yeasts were inhibited during 10 days by the use of antimicrobial active packaging made with silver nanoparticles. The obtained results showed that silver nanoparticles have an antimicrobial effect on different kinds of bacteria in fish products and the combined effect of silver nanoparticles and moisture absorber leads to achievement of better antibacterial results. This study suggests that the combination of silver nanoparticles and moisture absorbers are shown like a great option for preservation of food quality in elaborated tuna products.
\end{abstract}

\section{Keywords}

Active packaging, Antimicrobial, Food safety, Nanotechnology, Silver nanoparticles

\section{Introduction}

One of the main functions of food packaging is to provide passive protection against environmental agents that affect the shelf life of the products. The shelflife of packaged food depends on both the intrinsic and extrinsic factors. Intrinsic factors include $\mathrm{pH}$, water activity $\left(\mathrm{a}_{\mathrm{w}}\right)$, nutrient content, presence of antimicrobial compounds, redox potential, respiratory rate and the biological structure, whereas extrinsic factors include storage temperature, relative humidity and the surrounding gas composition [1].

Tuna is a fish with an excellent flavor, high market value and many health benefits due to its high content of polyunsaturated fatty acids [2]. In the case of fishes as tuna, the microorganisms are the main mechanism that leads to spoilage [3]. Traditional methods of preserving fish from the damaging effects of microbial growth include heat treatment, drying, freezing, refrigeration, irradiation, modified atmosphere packaging and addition of salts or antimicrobial agents [4].

In contrast to traditional packaging, which is required to be totally inert, active packaging is designed to interact actively with its contents and/or the surrounding environment [3, 6-8]. An interesting application of active packaging is the use of packaging materials containing antimicrobial compounds, to control microbial growth at the food surface [9]. Antimicrobial packaging include 
systems such as adding a sachet into the package, dispersing bioactive agents, coating bioactive agents on the surface of the packaging material, or utilizing antimicrobial macromolecules with film-forming properties or edible matrices [10]. A large number of agents with antimicrobial properties (ethanol, carbon dioxide, silver ions, chlorine dioxide, antibiotics, organic acids, essential oils and spices, etc.) have been tested in active packages. The purpose of their addition was to inhibit the growth of microorganisms that can lead to deterioration of foodstuffs (bacteria can also attack the packages affecting their functions and properties) [3].

Nanomaterials have a great scientific and technological interest because of their potential to exhibit new characteristics that cannot be achieved with micro materials [11-14]. The large surface area and high reactivity of Nano sized silver particles made them an interesting nanomaterial that exhibits remarkable physical, chemical, and biological properties as their high antimicrobial activity against bacteria and viruses $[15,16]$.

Two parameters are considered critical in the antimicrobial effect of silver nanoparticles: their size and their oxidation degree. Related to the size, smaller particles present more antibacterial activity, preferentially with a diameter of approximately 1-10 $\mathrm{nm}$, on the basis of equivalent silver mass content [15]. This is due to small particles have larger surface area in respect to its mass. However, a good dispersion of the nanoparticles is also required to assure the antibacterial activity in packaging, due to the possibility of aggregate formation that leads to the decrease in the number of nanoparticles that can interact with the membrane of the bacteria $[15,16]$.

Regarding to their oxidation degree, only the oxidized nanoparticles present antimicrobial activity, because to exert this effect the direct association of the oxidized nanoparticle and the bacteria is needed $[17,18]$. For example, oxidized silver produces a collapse of proton motive force in Vibrio cholerae because it induces a massive proton leakage through the membrane [19].

Different options have been developed in the last years in order to release the silver nanoparticles. One of the most useful is the release of silver, in form of zeolites, from the food contact material to exert its action on the surface of the food. This system is currently used by some commercial trademarks approved by FDA and EFSA [13]. Zeolites are open structured aluminosilicates with a negative charge that is compensated by cations such as sodium or silver. The cations are mobile and interchangeable (for example, $\mathrm{H}^{+} / \mathrm{H}_{2} \mathrm{O}$ ). Zeolites has been designed specifically to release silver ions and prevent microbial growth due to disruption of the microorganism RNA replication, inhibition of the respiratory chain enzymes, and the interferences in the membrane permeability $[3,15,20]$.

The present study has focused on the use of an antimicrobial package with silver zeolite and its combination with moisture absorbers, for the commercialization of refrigerated tuna snacks, and the effect on $\mathrm{pH}$, moisture, microbial growth, texture and color during their storage.

\section{Materials and Methods}

The analyzed snack is an elaborated product based in a cooked mixture of tuna, sunflower seed oil, salt and water with shape of cubes (each cube with a side of $18.5 \mathrm{~mm}$ and approx. $6 \mathrm{~g}$ of weight). Samples were supplied by Jealsa Rianxeira S.A.

The tuna snack (around $200 \mathrm{~g}$ ) was placed in polystyrene trays of $21 \times 12.5 \mathrm{~cm}\left(\right.$ Cryovac $\left.^{\oplus}\right)$ and packaged in a low density polyethylene bag (control sample). Samples have been made up using trays with Food Touch ${ }^{\mathrm{TM}}$ paper (Microbe guard ${ }^{\circledast}$ Corporation) (FT sample) and a combination of Food Touch $^{\mathrm{TM}}$ paper and cellulose pad (FT-c sample). All snack samples were stored at $5{ }^{\circ} \mathrm{C}$ and samples were removed at 0 , 6, 8, 10, 12 and 14 days. All the analysis were carried out in triplicate $(n=3)$.

\section{Water content}

Water content was determined by weight difference of the tuna snack (1-2 g) after $24 \mathrm{~h}$ at $105^{\circ} \mathrm{C}$. Results were calculated as $\mathrm{g}$ water $\mathrm{kg}^{-1}$ tuna snack.

\section{$\mathrm{pH}$}

The $\mathrm{pH}$ was measured directly on the tuna snack surface by a $\mathrm{pH}$ meter Crison GL22 with a $\mathrm{pH}$ electrode Crison 5232 (Crison Instruments, S.A., Barcelona, Spain). For each sample the average value was obtained from five different readings.

\section{Color measurements}

The color was measured by the method described by Prieto et al. [21]. A Konica Minolta colorimeter with a measuring head CR-300 (8-mm-diameter viewing area) was used to measure the color. The measuring conditions were fixed as follows: observer $2^{\circ}$ and illuminant D65, which represents a phase of daylight including the ultraviolet region spectrum. The measurements were made by spectral reflectance, using the diffuse illumination geometry with an integration sphere, covered with a white material and is observed with the specular component included in $0^{\circ}$ in relation to normal. The color measurements were analyzed in the CIELAB color space, which is organized with three axes in a spherical form: $L^{*}, a^{*}$ and $b^{*}$. The parameters are plotted on three orthogonal axes in a Cartesian coordinate system, where $L^{*}$ represents lightness, $\mathrm{a}^{*}$ represents the position between red and green, and $\mathrm{b}^{*}$ represents the position between yellow and blue. The $\mathrm{L}^{*}$ axis moves from top (100, white) to bottom (0, black), whereas $a^{*}$ and $b^{*}$ axes are associated with changes in redness-greenness (positive value of $\mathrm{a}^{*}$ is red and negative value of $\mathrm{a}^{*}$ is green) and in yellowness-blueness (positive value of $b^{*}$ is yellow and negative value of $b^{*}$ is blue). None of them have specific numerical limits. Additionally, the angular coordinates of chroma $\left[\mathrm{C}^{*}{ }_{\mathrm{ab}}=\left(\mathrm{a}^{* 2}+\mathrm{b}^{* 2}\right)^{1 / 2}\right]$ and hue angle $\left[\mathrm{h}_{\mathrm{ab}}=\arctan \left(\mathrm{b}^{*} / \mathrm{a}^{*}\right)\right]$ were also calculated. $\mathrm{C}^{*}$ ib the relative strength of a color, chroma or saturation of color, and $\mathrm{h}_{\mathrm{ab}}$ refers to the dominant wavelength, starts with $0^{\circ}$ and increases counterclockwise [22, 23].

In addition, the total color difference $(\Delta \mathrm{E})$ was calculated as:

$$
\Delta E=\sqrt{\left(L^{*}-L_{0}^{*}\right)^{2}+\left(a^{*}-a_{0}^{*}\right)+\left(b^{*}-b_{0}^{*}\right)^{2}}
$$


where $\mathrm{L}^{*}$ is the lightness of sample at time $t ; \mathrm{L}_{0}^{*}$ is the lightness of control sample at 0 day; $\mathrm{a}^{*}$ is the redness of sample at time $t ; a^{*}$ is the redness of control sample at 0 day; $b^{*}$ is the yellowness of sample at time $t ; a^{*}{ }_{0}$ is the yellowness of control sample at 0 day.

\section{Microbial count}

To evaluate the antimicrobial effect of silver nanoparticles, microbiological tests were done. The methodology was similar to those carried out by other authors [24] a total amount of 25 $\mathrm{g}$ of tuna snacks was collected aseptically and placed in a sterile plastic bag with $225 \mathrm{ml}$ of peptone water $10 \mathrm{~g} \cdot \mathrm{L}^{-1}$ in a vertical laminar-flow cabinet BIO II A (Telstar, Madrid, Spain). After $1 \mathrm{~min}$ in a stomacher Smasher (AES Chemunex, Combourg, FR), from the resulting homogenized dilution, appropriate progressive decimal dilutions were prepared, using the same diluent in order to evaluate the following microorganisms: i) Total Viable Counts in PCA medium, incubated $72 \mathrm{~h}$ at $30^{\circ} \mathrm{C}$ [25]; ii) Coliforms in VRBL medium, incubated 24 h at $37^{\circ} \mathrm{C}$ [26] and iii) Yeasts and moulds in YGC medium, incubated $120 \mathrm{~h}$ at $25^{\circ} \mathrm{C}$ [27]; Plates were inoculated, in triplicate, with $1 \mathrm{ml}$ of the corresponding dilutions.

Texture Profile Analysis (TPA)

The technique of large deformation single compression testing was employed on a TA-TX plus Texture Analyzer (Stable Micro Systems Ltd. Surrey, UK) [28]. The snack samples were taken from the refrigerator and placed at room temperature for $30 \mathrm{~min}$. Then, the snacks were characterized in the texture analyzer with a cylindrical probe (Ref. P/20). These samples were disposed on the platform vertically and horizontally and the probe was compressed into the sample at the rate of $1 \mathrm{~mm} \mathrm{~s}^{-1}$ with $5 \mathrm{~mm}$ penetration. Then, the probe was removed at $1 \mathrm{~mm} \mathrm{~s}^{-1}$ and the recovery of the sample was also monitored. Hardness, brittleness and adhesiveness have been determined.

\section{Statistical analyses}

With the obtained data, a two-way analysis of variance was done. Comparison of means was performed by the Least Significant Difference method. The Stat graphics plus 5.1 software for Windows (Statistical Graphics Corp, Warrenton, VA, United States) was used to carry out the tests. Differences were considered significant at $\mathrm{p}<0.05$ in all cases.

\section{Results and Discussion}

\section{Water content and $\mathrm{pH}$}

Water contents ranged between 621 and $615 \mathrm{~g} \mathrm{~kg}^{-1}$ during the assay. The $\mathrm{pH}$ was between 5.9 and 6.0. These data reflects that water content and $\mathrm{pH}$ determination have no significant differences $(\mathrm{p}<0.05)$ as a result of the time and type of package during refrigerated storage at $5{ }^{\circ} \mathrm{C}$. Based on these results, these two parameters were not significant as a physicochemical index of quality decay or in the prediction of the shelf life of tuna snacks [29].

\section{Color or CIELAB color parameters}

Color is a basic parameter in the evaluation of the foodstuffs quality. The CIELAB system is since 1976, the most widely used system for calculating color differences for most practical applications [21] by scientific community and industry. For tuna snack at time 0 , the cumulative averages of the CIELAB color system coordinates: $\mathrm{L}^{*}, \mathrm{a}^{*}$, and $\mathrm{b}^{*}$ were plotted (Figure 1). The first point of a horizontal asymptote represents the minimum number of measurements required to characterize the coordinates $\mathrm{L}^{*}, \mathrm{a}^{*}$, and $\mathrm{b}^{*}$ [21]. In figure 1 , horizontal asymptote is indicated by a marked segment. For this samples and taking into account that the used equipment has an 8-mm-diameter viewing area, the minimum number of measurements required to characterize the color is different for each of the CIELAB coordinates; so, the number of performed measures was 30 .
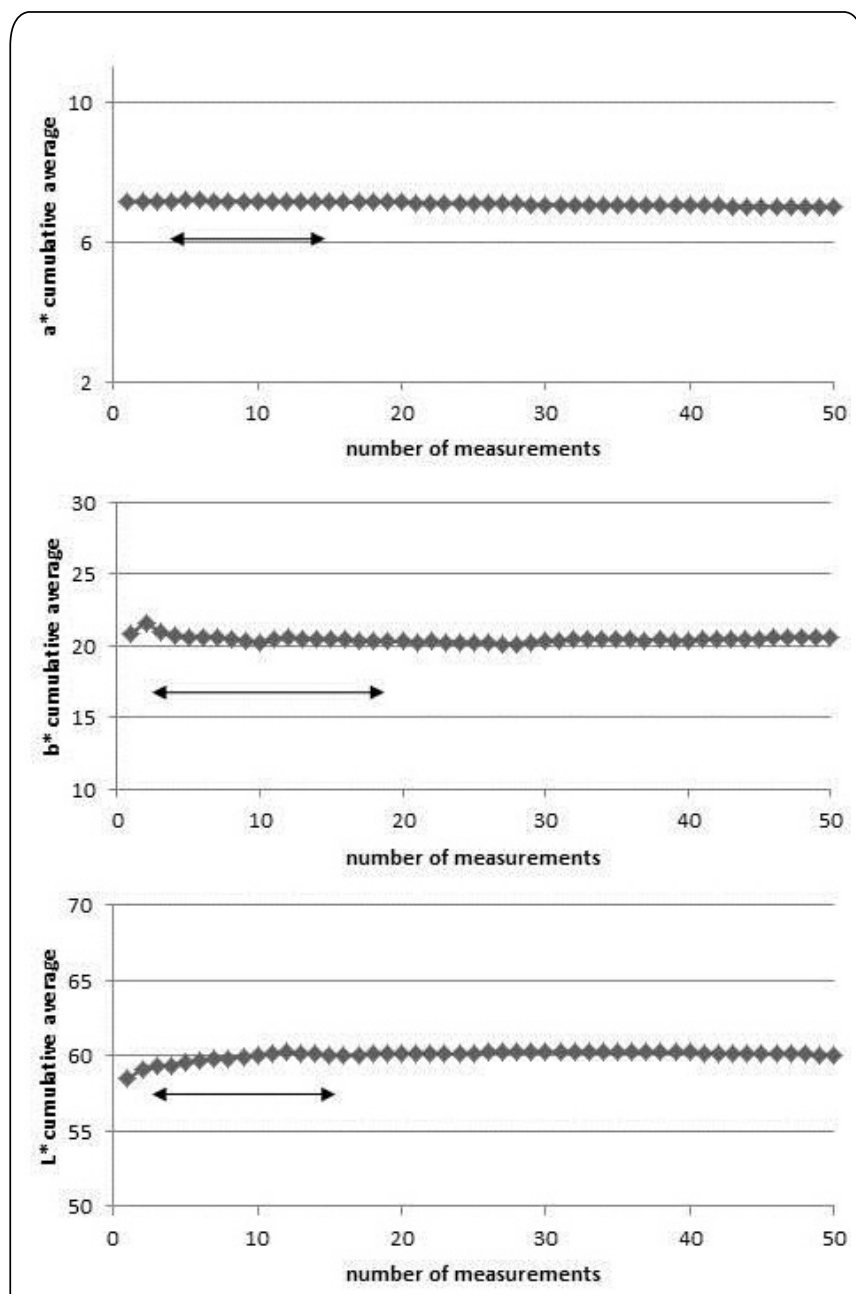

Figure 1: Cumulative averages of the CIELAB color system coordinates ( $L^{*}, a^{*}$, and $b^{*}$ ) in front of the number of measurements.

Statistical tests applied to the color data revealed significant differences for each CIELAB color parameter in relation to packaging type. The $\mathrm{L}^{*}$ parameter (lightness) decreased significantly in all types of samples with the storage (Table 1). The decrease of $\mathrm{L}^{*}$ was higher in control and FT sample, with values ranged from 59.69 to 55.48 and 60.80 $(\mathrm{t}=6)$ to $53.83(\mathrm{t}=14)$ CIELAB units, respectively. While the values of $\mathrm{L}^{*}$ in $\mathrm{FT}$-c sample had a minor decrease, with a range of variation between 60.42 on the sixth day and 57.65 CIELAB units at day 14. 


\begin{tabular}{|c|c|c|c|c|c|c|c|c|c|c|c|c|c|}
\hline \multirow{2}{*}{$\begin{array}{l}\text { Refrigerated } \\
\text { time (days) }\end{array}$} & \multicolumn{5}{|c|}{ Control Sample } & \multicolumn{4}{|c|}{ FT Sample } & \multicolumn{4}{|c|}{ FT-c Sample } \\
\hline & 0 & 6 & 8 & 10 & 14 & 6 & 8 & 10 & 14 & 6 & 8 & 10 & 14 \\
\hline$L^{*}$ & $59.69 \pm 0.59^{d}$ & $59.69 \pm 0.61^{d}$ & $59.95 \pm 0.60^{d}$ & $55.85 \pm 0.61^{\mathrm{b}}$ & $55.48 \pm 0.58^{\mathrm{ab}}$ & $60.80 \pm 0.60^{d}$ & $60.66 \pm 0.57^{d}$ & $56.62 \pm 0.61^{\mathrm{b}}$ & $53.83 \pm 0.61^{a}$ & $60.42 \pm 0.60^{\mathrm{d}}$ & $60.35 \pm 0.61^{d}$ & $55.59 \pm 0.61^{\mathrm{bc}}$ & $57.65 \pm 0.61^{c}$ \\
\hline$a^{*}$ & $6.88 \pm 0.06^{2}$ & $4.46 \pm 0.06^{b}$ & $3.87 \pm 0.06^{\mathrm{d}}$ & $3.04 \pm 0.06^{\mathrm{e}}$ & $2.56 \pm 0.06^{8}$ & $4.07 \pm 0.06^{c}$ & $3.81 \pm 0.06^{\mathrm{d}}$ & $2.78 \pm 0.06^{\mathrm{f}}$ & $2.37 \pm 0.06^{\mathrm{h}}$ & $4.20 \pm 0.06^{c}$ & $3.75 \pm 0.06^{\mathrm{d}}$ & $2.18 \pm 0.06^{j}$ & $2.45 \pm 0.06^{\text {sh }}$ \\
\hline$b^{*}$ & $20.44 \pm 0.20^{\mathrm{a}}$ & $20.38 \pm 0.21^{a}$ & $20.57 \pm 0.20^{a}$ & $19.31 \pm 0.21^{\mathrm{cd}}$ & $18.70 \pm 0.20^{\circ}$ & $20.22 \pm 0.20^{\mathrm{ab}}$ & $20.71 \pm 0.19^{a}$ & $18.85 \pm 0.21^{\text {de }}$ & $18.37 \pm 0.21^{e}$ & $20.62 \pm 0.21^{\mathrm{a}}$ & $20.45 \pm 0.20^{\mathrm{a}}$ & $18.67 \pm 0.21^{\mathrm{e}}$ & $19.66 \pm 0.21^{\mathrm{bc}}$ \\
\hline $\mathrm{C}_{\mathrm{ab}}^{*}$ & $21.62 \pm 0.19^{a}$ & $20.87 \pm 0.20^{b}$ & $20.93 \pm 0.20^{b}$ & $19.56 \pm 0.20^{\text {cd }}$ & $18.80 \pm 0.19^{f f}$ & $20.63 \pm 0.19^{b}$ & $21.06 \pm 0.18^{b}$ & $19.12 \pm 0.20^{\text {de }}$ & $18.53 \pm 0.20^{f}$ & $21.04 \pm 0.20^{b}$ & $20.79 \pm 0.20^{\mathrm{b}}$ & $18.97 \pm 0.20^{\text {ef }}$ & $19.82 \pm 0.20^{c}$ \\
\hline$h_{a b}$ & $72.40 \pm 0.42^{a}$ & $77.61 \pm 0.44^{b}$ & $79.28 \pm 0.43^{c}$ & $81.65 \pm 0.44^{d}$ & $83.50 \pm 0.42^{c}$ & $78.62 \pm 0.43^{\mathrm{bc}}$ & $79.54 \pm 0.40^{c}$ & $82.61 \pm 0.44^{\text {de }}$ & $83.33 \pm 0.44^{e}$ & $78.47 \pm 0.44^{k c}$ & $79.58 \pm 0.43^{c}$ & $85.13 \pm 0.44^{e}$ & $83.08 \pm 0.44^{f}$ \\
\hline
\end{tabular}

Different superscript letters indicate significant differences $(\mathrm{p}<0.05)$ between the values of CIELAB color parameters in control sample, Ft sample and FT-c sample.

The value of the parameter $\mathrm{a}^{*}$ varies from positive values (redness) to negative values (greenness). Value of $\mathrm{a}^{*}$ at zero time was 6.68 and descending from $4.46(t=6)$ to $2.56(t=14)$ in control sample. In FT sample, the values ranged between $4.07(\mathrm{t}=6)$ and $2.37(\mathrm{t}=14)$, and between $4.20(\mathrm{t}=6)$ and 2.45 $(t=14)$ for FT-c sample. Nevertheless, only the significant differences from $t=8$ could be attributed to the packaging, according to the statistical analysis. This red color is generated during the processing of tuna, when the oxygen reacts with the myoglobin to form oxy-myoglobin (red pigment). But, this red color disappears in function of time due to the reaction of oxymyoglobin molecules with oxygen to produce met-myoglobin (brown pigment). This conduces to a change in the color of tuna muscle from red to various shades of brown [29, 30]. Less significant was the effect of package type and time on $b^{*}$. Positive values of $b^{*}$ are associated to yellowness and negative values are associated to blueness. Values of $b^{*}$ began at 20.44 , and the values ranged between 20.38 on day 6 and 18.70 for control sample on fourteenth day, $20.22(\mathrm{t}=6)$ and $18.37(\mathrm{t}=$ 14) for FT sample, and between $20.62(t=6)$ and $19.66(t=$ 14) for FT-c sample.

The color parameters most closely related to color perception are the angular coordinates of chroma and hue angle [23]. In all cases and samples, a decrease of chroma is observed. Results for chroma $\mathrm{C}^{*}{ }_{\mathrm{ab}}$, showed a similar pattern to that observed for $\mathrm{b}^{*}$ and $\mathrm{a}^{*}$, with values that began at 21.62 and fluctuated between 20.87 and 18.80 CIELAB units (from sixth to fourteenth day) for control sample, 20.63 and 18.53 for FT sample, and between 21.04 and 19.82 for FT-c sample. Hue angle $\left(h_{a b}\right)$ of samples increased significantly with the time of storage, without any significant difference between the different samples along the study; The value on day 0 was $72.40^{\circ}$, and from day 6 to day 14 , the $\mathrm{h}^{*}$ values ranged between $77.61^{\circ}$ and $83.50^{\circ}$ in control sample, $78.62^{\circ}$ and $83.33^{\circ}$ in FT sample, and between $78.47^{\circ}$ and $83.08^{\circ}$ for FT-c sample.

To describe the total change in the color of tuna snack, the combination of CIELAB parameters $L^{*}$, $a^{*}$ and $b^{*}$, were determined in terms of total color difference $(\Delta \mathrm{E})$ and plotted in figure 2. As it can be observed, $\Delta \mathrm{E}$ increases with time of storage in all samples. At the end of storage, the increase of $\Delta \mathrm{E}$ in control and FT sample was higher than in FT-c sample. The change in the CIELAB parameters may be due to the variation in the microbial load [21], the integrity of sample, the deterioration of the pigments and/or changes in some constituents of the sample. Thus, the use of antimicrobial paper and cellulose pad gave rise to the lowest change in $\Delta \mathrm{E}$, $\mathrm{C}^{*}{ }_{\mathrm{ab}}, \mathrm{L}^{*}, \mathrm{a}^{*}$ and $\mathrm{b}^{*}$ values.

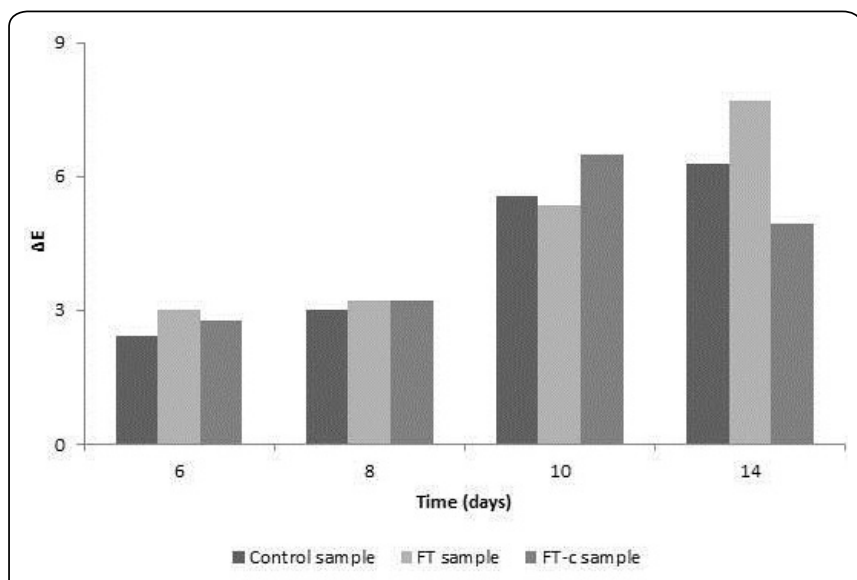

Figure 2: Values of the Total Color Difference $(\Delta \mathrm{E})$ during the samples storage.

\section{Antimicrobial effect}

Active packaging containing antimicrobial compounds is a promising application to control undesirable microbial growth in foods [9]. The composition of the microbial load presents in the tuna snack is relatively complex and with different levels of resistance to silver nanoparticles. In control samples, the microbial count exhibited an increase tendency with the storage time. Packages with silver nanoparticles and its combination with cellulose pads resulted in lower microbial counts.

Figure 3 shows the evolution of the total viable counts in the different package options during the 14 days of study. The results showed an increasing number of bacteria in the control sample. The same tendency has been followed by FT and FT-c samples; however, the count has been lower during the first eight days of the study. After this time, the inhibitory effect of the silver nanoparticles disappears and the bacteria load raises to the control levels. 


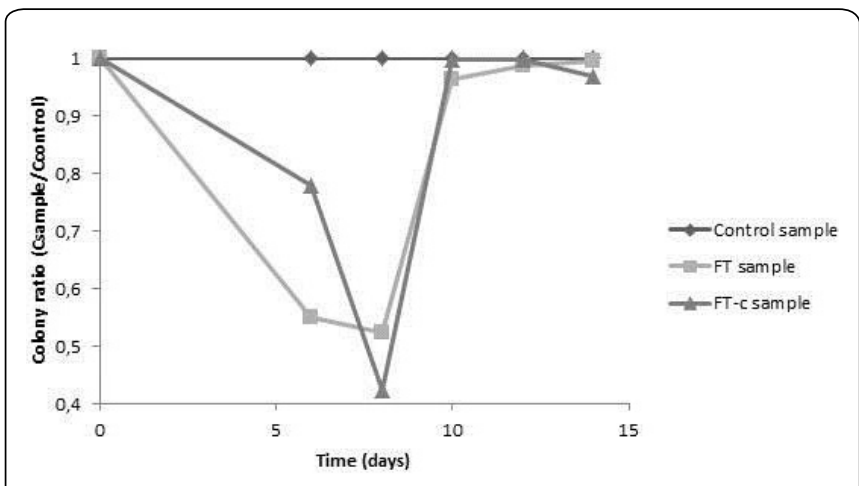

Figure 3: Total Viable Counts (TVC) evolution during the assay.

The presence and evolution of enterobacteria, molds and yeasts is a good way to check the elaboration process and quality of foods. The evolutions of enterobacteria, molds and yeasts as a function of time using the three different packages in samples of tuna snacks stored at $5{ }^{\circ} \mathrm{C}$ are shown in figure 4 and 5, respectively (data counts below the detection limit are represented as 0 ). The enterobacteria in the control tuna snack samples increased constantly after the sixth day until the end of the study. Moreover, the effect of FT and FT-c samples over growth of enterobacteria was remarkable. It can be seen that enterobacteria do not grow in snack tuna samples packaged with nanoparticles of silver.

On the other hand, the microbial count of moulds and yeasts, originally presents in very low number, increase with
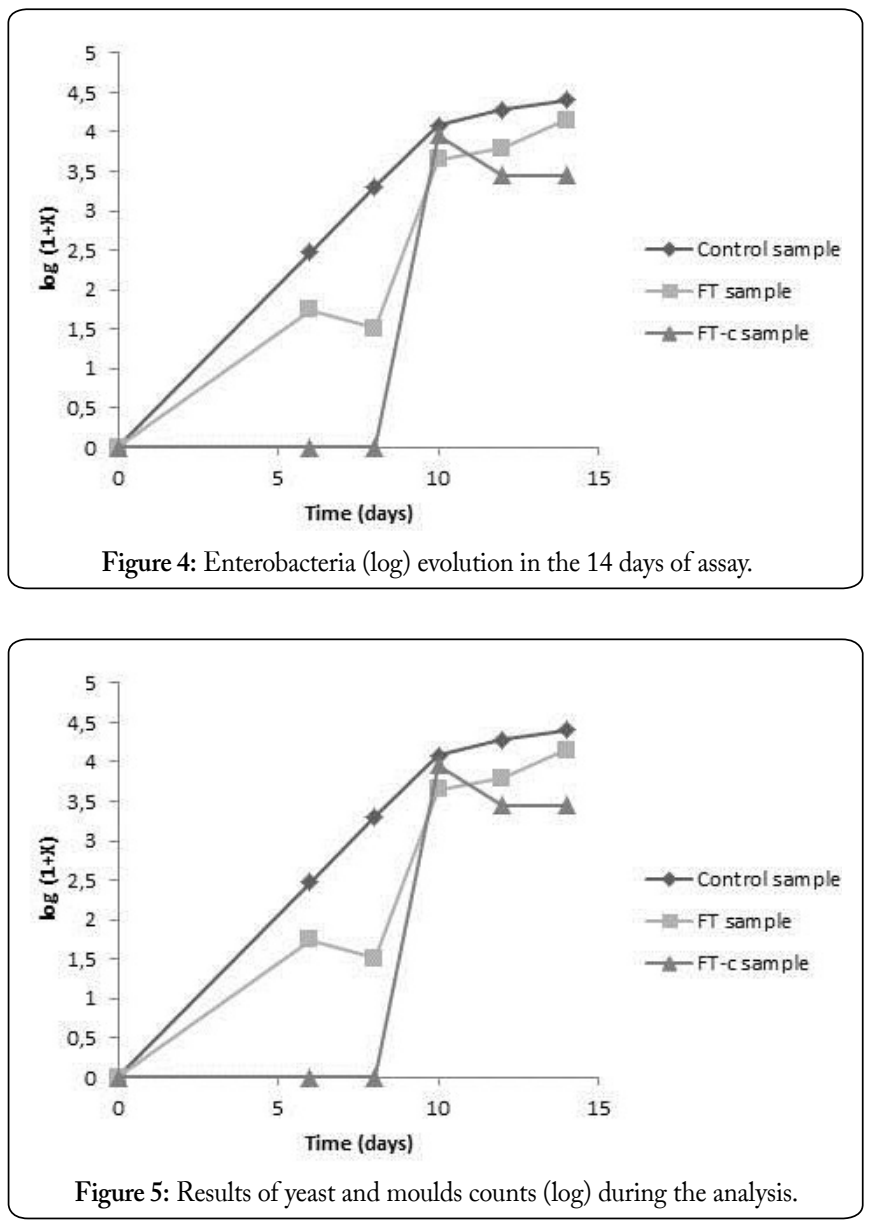

the storage time since the first day for control and FT sample (figure 5), but the FT sample always present lower counts of moulds and yeast than the control, until the tenth day. However, the combination of silver nanoparticles and cellulose pads (FT-c samples) inhibited the growth of moulds and yeasts so it could be a good option. However, after the first ten days the count of molds and yeast reaches to levels as the control and FT samples.

The antimicrobial effectiveness of packages that contain oxidized silver nanoparticles is related to its ability to induce damage to cell membranes, oxidative stress, and interferences in the membrane permeability, inhibition of the respiratory chain at a low potential point and/or interactions of silver ions with proteins and enzymes over different kinds of bacteria as gram negative bacteria, mould and yeasts $[13,15,16,20,31-33]$.

From these results it can be concluded that the shelf life of tuna snack can be prolonged by using antimicrobial active packaging with silver nanoparticles. The combination of silver nanoparticles and moisture absorber leads to better antibacterial results.

\section{Texture profile analysis}

The TPA imitates the jaw action, extracting from the resulting force-time curve a number of textural parameters that correlate well with the sensory evaluation. In our case, the studied parameters were: hardness (the height of the force peak on the first compression cycle), brittleness (the force of the significant break in the curve on the first bite) and adhesiveness (the negative force area of the first bite represented the work necessary to pull the compressing plunger away from the sample) [34]. Figure 6 shows hardness determination. It can be observed that hardness increases with time in all samples. From day 8 a small increase in the hardness in FT samples is observed. In the case of FT-c samples, the hardness was similar to the control samples. With respect to brittleness, samples did not show any fracture point in the TPA curves.

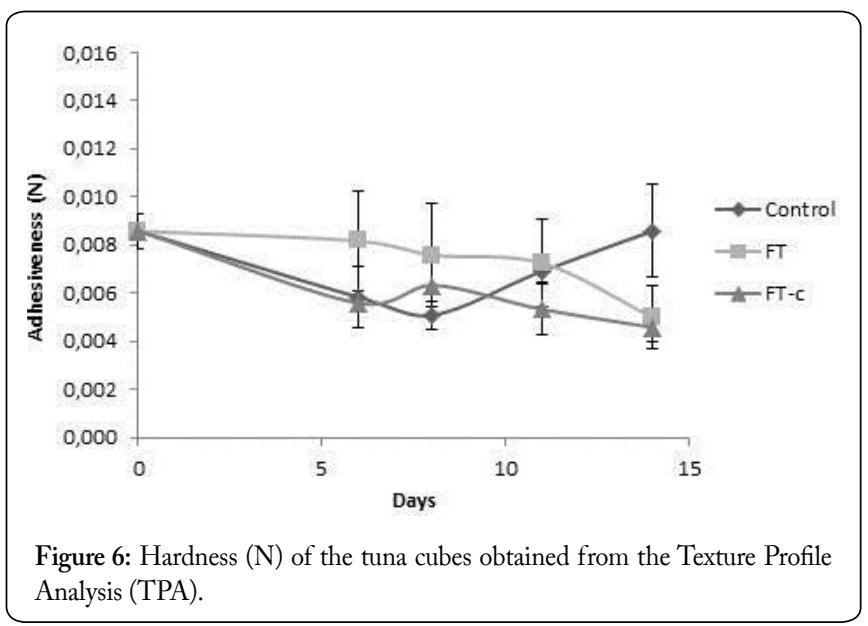

The adhesiveness (Figure 7) is a complex property that is the summary of a balance between cohesive and adhesive forces where it contributes others properties as the viscosity and viscoelasticity [35]. During the first eight days, a negligible decrease in the adhesiveness of the FT-c and control samples is observed. The eighth day marked a turning point in control 
samples due to the values of adhesiveness began to increase until the end of the study, while in FT and the FT-c samples the control samples an increase in adhesiveness values is observed. From day 8, in the samples FT and FT-c, a gradual decrease of adhesiveness values is present throughout the study. López-Caballero et al. [36] observed that these changes in the adhesiveness of the samples are due to cleavage of strong bonds as a result of microbial action resulting in degradation in proteins.

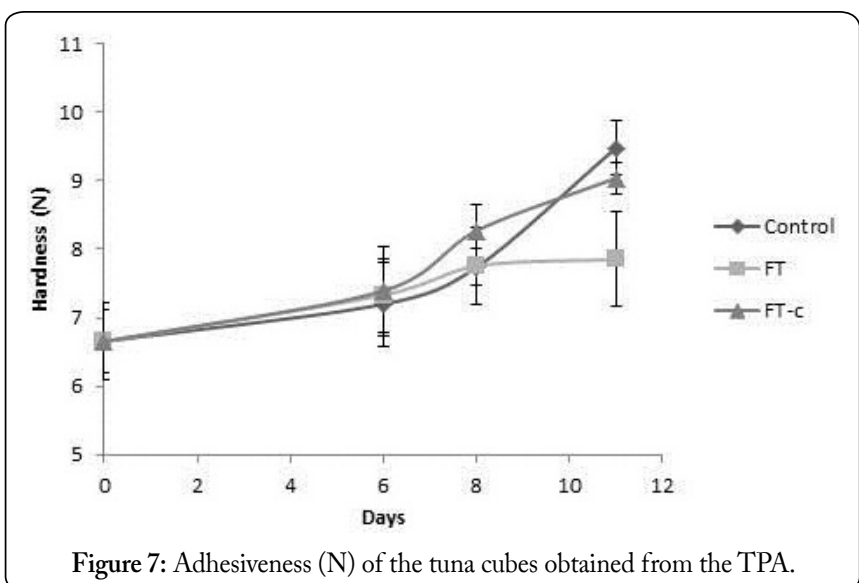

\section{Conclusions}

The interaction between packaging and refrigerated storage time affects the parameters studied in this work. The results obtained show that the antimicrobial active packaging could be a very useful and effective tool for extending the shelf life of tuna snacks. Water contents and $\mathrm{pH}$ values were not significantly affected by package type and storage time. However, the color, texture and microbiology analysis, showed significantly better results for the samples that combined silver nanoparticles and moisture absorbers, with a remarkable suppression of enterobacteria growth. In any case, the potential use of this combination of systems may be limited by their cost; so this should be taken into account for future works.

\section{Acknowledgement}

This work was co-funded by Jealsa Rianxeira and Imasde Agroalimentaria, S.L. (project "Proyecto Integrado Tecnologías Emergentes de Procesado de Alimentos de Galicia IDI20081097"). The authors are grateful to the Ministerio de Economía y Competitividad for the predoctoral fellowship FPI [reference number BES-2012-051993] awarded to Miguel Ángel Lago; and also to the A1ßan Programme, the European Union Programme of High Level Scholarships for Latin America, scholarship No. E04D041673VE. Raquel Sendón is grateful to the 'Parga Pondal' programme financed by the Consellería de Innovación e Industria, Xunta de Galicia for her postdoctoral contract. The authors appreciates to Daniel Vázquez Nión and Beatriz Prieto Lamas (Grupo GEMAP), Carmen Álvarez-Lorenzo, María Pernas Carralero, Cristina Casal, Patricia Blanco and Gonzalo Hermelo for their technical support.

\section{References}

1. Day BPF. 2008. Active packaging of food. In: Kerry J, Butler P (eds) Smart Packaging Technologies for Fast Moving Consumer Goods. John Wiley \& Sons, Ltd, Chichester, UK. doi: 10.1002/9780470753699.ch1

2. Chagan L, Loselovich A, Asherova L, Cheng J. 2002. Use of alternative pharmacotherapy in management of cardiovascular diseases. $\mathrm{Am} \mathrm{J}$ Manag Care 8(3): 270-285.

3. Pereira de Abreu D, Paseiro Losada P, Maroto J, Cruz JM. 2010. Lipid damage during frozen storage of Atlantic halibut (Hippoglossus hippoglossus) fillets packaged with an active packaging film containing antioxidants. Food Chem 126(1): 315-320. doi: 10.1016/j. foodchem.2010.10.048

4. Galotto MJ, Guarda A, de Dicastillo CL. 2015. Antimicrobial active polymers in food packaging. In: Cirillo G, Spizzirri UG, Iemma F (eds) Functional Polymers in Food Science: From Technology to Biology. John Wiley \& Sons, Inc., Hoboken, NJ, USA, pp 323-353. doi: 10.1002/9781119109785.ch10

5. Pereira de Abreu D, Cruz JM, Paseiro Losada P. 2012. Active and intelligent packaging for the food industry. Food Rev Int 28(2): 146187. doi: $10.1080 / 87559129.2011 .595022$

6. Biji KB, Ravishankar CN, Mohan CO, Srinivasa Gopal TK. 2015. Smart packaging systems for food applications: a review. J Food Sci Technol 52(10): 6125-6135. doi: 10.1007/s13197-015-1766-7

7. Ghaani M, Cozzolino CA, Castelli G, Farris S. 2016. An overview of the intelligent packaging technologies in the food sector. Trends in Food Sci Tech 51: 1-11. doi: 10.1016/j.tifs.2016.02.008

8. Restuccia D, Puoci F, Parisi OI, Picci N. 2015. Food applications of active and intelligent packaging: legal issues and safety concerns. In: Cirillo G, Spizzirri UG, Iemma F (eds) Functional Polymers in Food Science: From Technology to Biology. John Wiley \& Sons, Inc., Hoboken, NJ, USA, pp 401-429. doi: 10.1002/9781119109785.ch12

9. Devlieghere F, Vermeiren L, Jacobs M, Debevere J. 2000. The effectiveness of hexamethylenetetramine-incorporated plastic for the active packaging of foods. Packag Technol Sci 13(3): 117-121.

10. Coma V. 2008. Bioactive packaging technologies for extended shelf life of meat based products. Meat Sci 78(1-2): 90-103. doi: 10.1016/j. meatsci.2007.07.035

11. Azevedo HMC. 2009. Nano composites for food packaging applications. Food Res Int 42(9): 1240-1253. doi: 10.1016/j.foodres.2009.03.019

12. Pereira de Abreu D, Paseiro P, Angulo I, Cruz J. 2007. Development of new polyolefin films with nanoclays for application in food packaging. Eur Polym J 43(6): 2229-2243. doi: 10.1016/j.eurpolymj.2007.01.021

13. Silvestre C, Duraccio D, Cimmino S. 2011. Food packaging based on polymer nanomaterials. Prog Polym Sci 36(12): 1766-1782. doi: 10.1016/j.progpolymsci.2011.02.003

14. Singh PK, Jairath G, Ahlawat SS. 2015. Nanotechnology: a future tool to improve quality and safety in meat industry. J Food Sci Technol 1-11. doi: 10.1007/s13197-015-2090-y

15. Lok CN, Ho M, Chen R, He QY, Yu WY, et al. 2007. Silver nanoparticles: partial oxidation and antibacterial activities. J Biol Inorg Chem 12(4): 527-534. doi: 10.1007/s00775-007-0208-z

16. Pal S, Tak YK, Song JM. 2007. Does the antibacterial activity of silver nanoparticles depend on the shape of the nanoparticle? A study of the gram-negative bacterium Escherichia coli. Appl Environ Microb 73(6): 1712-1720. doi: 10.1128/AEM.02218-06

17. Djokic SS, Burrell RE. 1998. Behavior of silver in physiological solutions.J Electrochem Soc 145(5): 1426-1430. doi: 10.1149/1.1838499

18. Morones J, Elechiguerra J, Camacho A, Holt K, Kouri J, et al. 2005. The bactericidal effect of silver nanoparticles. Nanotechnology 16(10): 23462353. doi: 10.1088/0957-4484/16/10/059

19. Dibrov P,Dzioba J, Gosink K, Häse C. 2002. Chemiosmotic mechanism of antimicrobial activity of $\mathrm{Ag}^{+}$in Vibrio cholerae. Antimicrob Agents $\mathrm{Ch}$ 46(8): 2668-2670. doi: 10.1128/AAC.46.8.2668-2670.2002 
20. Sharma VK, Yngard RA, Lin Y. 2009. Silver nanoparticles: Green synthesis and their antimicrobial activities. Adv Colloid Interfac 145(12): 83-96. doi: 10.1016/j.cis.2008.09.002

21. Prieto B, Sanmartín P, Silva B, Martínez-Verdú F. 2010. Measuring the color of granite rocks: A proposed procedure. Color Res Appl 35(5): 368375. doi: $10.1002 / \mathrm{col} .20579$

22. Sanmartín P, Aira N, Devesa-Rey R, Silva B, Prieto B. 2010. Relationship between color and pigment production in two stone biofilm-forming cyanobacteria (Nostoc sp. PCC 9104 and Nostoc sp. PCC 9025). Biofouling 26(5): 499-509. doi: 10.1080/08927011003774221

23. Sanmartín P, Villa F, Silva B, Cappitelli F, Prieto B. 2011. Color measurements as a reliable method for estimating chlorophyll degradation to phaeopigments. Biodegradation 22(4): 763-771. doi: $10.1007 / \mathrm{s} 10532-010-9402-8$

24. Gómez-Estaca J, López de Lacey A, López-Caballero ME, GómezGuillén MC, Montero P. 2010. Biodegradable gelatine-chitosan films incorporated with essential oils as antimicrobial agents for fish preservation. Food Microbiol 27(7): 889-896. doi: 10.1016/j. fm.2010.05.012

25. ISO 4833:2003. Microbiology of food and animal feeding stuffs - Horizontal method for the enumeration of microorganisms Colony-count technique at $30{ }^{\circ} \mathrm{C}$. International Organization for Standardization, Geneva, Switzerland.

26. ISO 4832:2006. Microbiology of food and animal feeding stuffs Horizontal method for the enumeration of coliforms - Colony-coun technique. International Organization for Standardization, Geneva, Switzerland.

27. ISO 7954:1987. Microbiology - General guidance for enumeration of yeasts and moulds - Colony count technique at $25^{\circ} \mathrm{C}$. International Organization for Standardization, Geneva, Switzerland.
28. Rahman M, Al-Waili H, Guizani N, Kasapis S. 2007. Instrumentalsensory evaluation of texture for fish sausage and its storage stability. Fisheries Sci 73(5): 1166-1176. doi: 10.1111/j.1444-2906.2007.01449.x

29. Torrieri E, Carlino PA, Cavella S, Fogliano V, Attianese I, et al. 2011. Effect of modified atmosphere and active packaging on the shelf-life of fresh bluefin tuna fillets. J Food Eng 105(3): 429-435. doi: 10.1016/j. jfoodeng.2011.02.038

30. Tajima G, Shikama K. 1987. Autoxidation of oxymyoglobin. An overall stoichiometry including subsequent side reactions.J Biol Chem 262(26): 12603-12606.

31. Kim JS, Kuk E, Yu KN, Kim JH, Park SJ, et al. 2007. Antimicrobial effects of silver nanoparticles. Nanomed Nanotechnol 3(1): 95-101. doi: 10.1016/j.nano.2006.12.001

32. Navarro E, Piccapietra F, Wagner B, Marconi F, Kaegi R, et al. 2008. Toxicity of silver nanoparticles to Chlamydomonas reinhardtii. Envir Sci Tech 42(23): 8959-8964. doi: 10.1021/es801785m

33. Ramachandraiah K. Han SG, Chin KB. 2015. Nanotechnology in meat processing and packaging: potential applications- a review. Asian Austral J Anim 28(2): 290-302. doi: 10.5713/ajas.14.0607

34. Bourne MC. 2002. Food Texture and Viscosity ( $2^{\text {nd }}$ edition): Concept and Measurement. Academic Press, New York, USA. doi: 10.1016/ B978-012119062-0/50000-0

35. Adhikari B, Howes T, Bhandari BR, Truong V. 2001. Stickiness in foods: A review of mechanisms and test methods. Int J Food Prop 4(1): 1-33. doi: 10.1081/JFP-100002186

36. López-Caballero ME, Gómez-Guillén MC, Pérez-Mateos M, Montero E. 2005. A functional chitosan-enriched fish sausage treated by high pressure. J Food Sci 70(3): M166-M171. doi: 10.1111/j.13652621.2005.tb07145.x 